\section{Two inexpensive raw-meat dispensers}

\author{
GRAHAM R. MARTIN \\ Liniversity of Exeter. Exeter. Engiand
}

The two raw-meat dispensers described here were built for the automatic presentation of raw meat as reinforcement in a series of experiments, using operant conditioning techniques, investigating the visual capacities of tawny owls (Strix aluco). Both feeders utilize the adhesive property of meat as an advantage and have been satisfactorily used with various types of meat in different sized portions. Feeder 1 is best suited for pilot studies investigating the feasibility of conducting experiments with a new carnivorous species. It is very compact, and can be built in a few hours for little more than the cost of an electric motor. Feeder 2 has no limitation upon the number of reinforcers it can be built to dispense. It occupies little space behind the apparatus interface. leaving adequate room for stimulus presentation equipment. Construction takes little more than 2 days, and the cost is minimal. Although the designs are not unique, these feeders have been

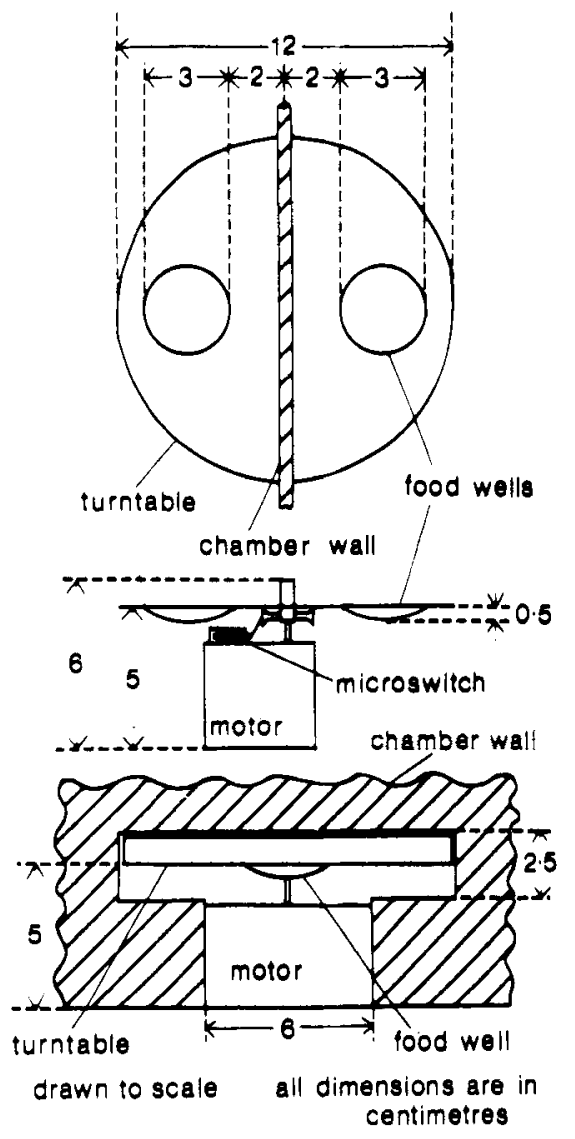

Fig. 1. Diagrams of Feeder 1. Top, plan view; middle, side elevation: bottom, front view showing the feeder in position in the apparatus interface. Dimensions are in centimeters. Drawn to scale. suciessfully employed in a number of experiments with tawny owls (Martin. 1973. 1974) and have been in daily use for 2 years with more than 80.000 faultless reinforcer deliveries. Paste and liquid meat feeders permitting programmable amounts of meat have been reported in this Journal and elsewhere.

\section{FEEDER 1}

The design of Feeder 1 is shown diagrammatically in Fig. 1. It consists of an aluminum, horizontally mounted circular turntable, bearing two symmetrically placed food wells. One food well extends into the apparatus chamber, while the other is outside, where it can be loaded. The turntable is rotated by the direct drive of a small electric motor (Crouzet. Type 82332). Current to the motor is switched through a hold circuit that is broken by closing a microswitch attached to the motor frame. The microswitch is closed by a screw attached to the drive shaft. Two screws are positioned either side of the driveshaft such that the microswitch is closed every half revolution of the turntable. Since the meat adheres to the aluminum, rotation speed can be fast and delivery completed in half a second. The apparatus is small enough to be positioned a few centimeters below a stimulus panel or manipulandum.

\section{FEEDER 2}

The basic design of Feeder 2 (Fig. 2) is that of a conveyor belt bearing a number of aluminum food cups. one of which extends into the experimental chamber at a time. A small electric motor drives the conveyor belt, and electrical control circuitry, similar to that used in Feeder 1, ensures that one loaded cup steps forward into the chamber at a time. The belt is made of a double layer of webbing material, and its length depends upon the number of food cups required. The motor (Crouzet. Type 392) provides the drive to the rear roller via a gear drive. These are mounted upon a frame that slides within the fixed frame in which the whole device is mounted. The sliding frame is connected by a spring to the fixed frame, and the spring's tension can be adjusted to ensure that the belt is of the correct tension. The rollers are of wood and have aluminum flanges to ensure that the belt remains central upon the rollers. Food cups are attached to the belt with 6BA nuts and bolts. The heads of these bolts close a microswitch as they pass, breaking the hold circuit through which the motor is switched. Pieces of raw meat readily adhere to the aluminum cups and do not fall off, even when the cups are inverted at the rear roller. All cups can be loaded at the start of an experimental session. Servicing is minimal, and the cups are easily accessible for cleaning. Reinforcer delivery takes less than $1 \mathrm{sec}$. The apparatus is narrow enough to be positioned between a pair of stimulus panels to enable simultaneous visual discrimination experiments to be performed. 


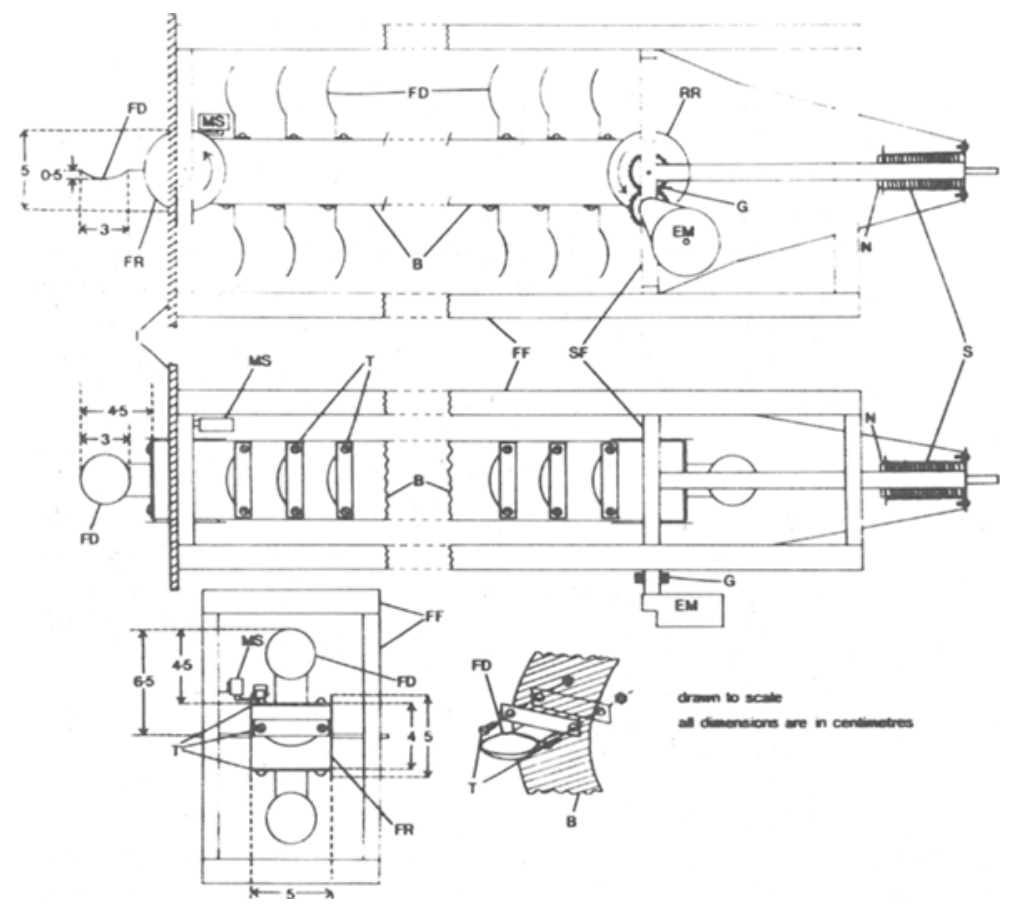

Fig. 2. Diagrams of Feeder 2. Top, side elevation: middle, plan view; lower left, front elevation: lower right, the method of attachment of a food cup to the belt. B, webbing belt; EM, electric motor; FD, food dishes; FF, fixed frame by which the feeder is attached to the apparatus interface; FR, front roller: $G$, gear drive from electric motor to rear roller; I. interface of experimental chamber: MS, microswitch: $\mathbf{N}$. nut to adjust tension in spring: RR. rear roller: S, spring providing the correct tension in the belt: $T$, nuts securing the food dishes to the belt. Dimensions are in centimeters Drawn to scale.

\section{REFERENCES}

Martin, G. R. Operant responding and stimulus control in tawny owls (Strix aluco). Journal of Comparative \& Physiological Psychology, 1973, 85, 346-352.

Martin. G. R. Color vision in the tawny owl (Strix aluco).
Journal of Comparative \& Physiological Psychology, 1974. in press.

(Received for publication July 20, 1973; revision received October 19,1973 .) 